\title{
Challenges in Management of Tracheobronchial Foreign Bodies with Delayed Presentation: An Institutional Experience
}

\author{
Darwin Kaushal ${ }^{10}$ Amit Goyal ${ }^{10}$ Kapil Soni ${ }^{10}$ \\ Prawin Kumar $^{20}$ Sameema V. Vaithankalath ${ }^{10}$
${ }^{1}$ Department of Otorhinolaryngology, All India Institute of Medical Sciences, Jodhpur, Rajasthan, India
2 Department of Pediatrics, All India Institute of Medical Sciences, Jodhpur, Rajasthan, India

\author{
Bikram Choudhury ${ }^{1 \odot}$ Nithin Prakasan Nair ${ }^{1 \odot}$
}

Int Arch Otorhinolaryngol 2022;26(1):e5-e9.

\begin{abstract}
Address for correspondence Darwin Kaushal, MS, ENT, DNB, MNAMS, Department of Otorhinolaryngology, AlIMS, Jodhpur, Rajasthan, India, Pin- 342005 (e-mail: darwin@aiimsjodhpur.edu.in).
\end{abstract}

\begin{abstract}
Keywords

- bronchoscopy

- foreign body

- bronchial

- trachea

- bronchoscope

- consolidation

Introduction Airway foreign bodies are emergencies involving multidisciplinary departments like Pediatrics, Aneasthesiology and Otorhinolaryngology. It is always a challenge to diagnose and manage patients who present late to our emergencies.

Objective In the present study, we aim to analyze the various challenges faced during the management of tracheobronchial foreign bodies with delayed presentation.

Methods A retrospective hospital record-based analysis of patients who presented to us with tracheobronchial foreign bodies from January 2017 to February 2020 was performed. All patients until the age of 16 years old were included in the present study. We assessed the demographics, preoperative, intraoperative and postoperative data of the patients.

Results Seventeen patients were analyzed in the study. Among these, $44.4 \%$ of the patients had delayed presentation ( $>1$ month). The majority of the patients had an organic foreign body (Supari or betel nut). All patients underwent rigid bronchoscopy, followed by optical forceps-assisted removal of the foreign body. A total of $82 \%$ of the patients had granulations around the foreign body.

Conclusion Management of delayed presentation tracheobronchial foreign body is a big challenge for Otorhinolaryngologists. The key factors for preventing complications in the definitive management of tracheobronchial foreign bodies are preoperative planning, multi-discipline teamwork, surgeon expertise and technique.
\end{abstract}

\section{Introduction}

Tracheobronchial foreign body aspiration is one of the common life-threatening emergencies in children. It is one of the leading causes of mortality among the pediatric population. A developing child always tends to explore objects and insert them in the mouth. This tendency leads to more chances of foreign body aspiration. It requires urgent removal of the foreign body to prevent complications and to reduce mortality. ${ }^{1}$ According to the literature, children $<3$ years old are more prone to foreign body aspiration. ${ }^{2}$ Narrow and short upper airway and incomplete protective mechanisms may also add to the morbidity. received

May 31, 2020

accepted

September 3, 2020

published online

February 19, 2021
DOI https://doi.org/ 10.1055/s-0040-1718964. ISSN 1809-9777.

\footnotetext{
(c) 2021. Fundação Otorrinolaringologia. All rights reserved.

This is an open access article published by Thieme under the terms of the Creative Commons Attribution-NonDerivative-NonCommercial-License, permitting copying and reproduction so long as the original work is given appropriate credit. Contents may not be used for commercial purposes, or adapted, remixed, transformed or built upon. (https://creativecommons.org/ licenses/by-nc-nd/4.0/)

Thieme Revinter Publicações Ltda., Rua do Matoso 170, Rio de Janeiro, RJ, CEP 20270-135, Brazil
} 
The severity of the clinical manifestation depends on the nature of the foreign body, site and degree of obstruction and duration of foreign body retention in the tracheobronchial tree. ${ }^{3}$ Clinically, these patients may present with a history of choking episodes, sudden onset cough and respiratory distress. Other clinical symptomatology includes wheezing, decreased breath sounds, stridor, unilateral collapse, hyperinflation of the lung and recurrent pneumonia. Sometimes, the diagnosis may be delayed due to several factors such as atypical history, absence of witnessed choking, lack of awareness among parents about the significance of the conditions, lack of experience among physicians, etc. Delayed diagnosis can lead to complications such as recurrent pneumonia, bronchiectasis, emphysema and even death. ${ }^{4}$ The present study aims to present our experience in managing tracheobronchial foreign body with delayed presentation presenting at a Tertiary Care Hospital.

\section{Materials and Methodology}

The present study is a retrospective hospital record-based analysis of 17 pediatric patients who presented to (All India Institute of Medical Sciences Jodhpur) with a tracheobronchial foreign body. We reviewed patients who presented to us from January 2017 until February 2020. The patients included in the present study were those patients in whom there was not a clear-cut history of foreign body aspiration. Patients until the age of 16 years old were included in the study.

From hospital records, we collected various data like age, gender, presenting complaints, the period between probable aspiration and diagnosis. We also collected the preoperative imaging and diagnostic bronchoscopy details (if performed). Intraoperative findings including the site of obstruction, presence of granulations, type of foreign body, the postoperative need of mechanical ventilation and duration of hospital stay were also noted.

Most of the patients were referred to the Department of Otorhinolaryngology from the Department of Pediatrics. We also have included doctor-related factors in the study, such as surgical technique, anesthesia technique and use of optical forceps. Some of the patients were evaluated with flexible diagnostic bronchoscopy, as the physician was not sure of the diagnosis. All patients underwent rigid bronchoscopy and foreign body removal under general anesthesia.

\section{Results}

There was no gender predominance. Eleven patients were in the age range between 1 and 5 years old. The majority of the patients had a foreign body in the right bronchus (70.5\%) as compared with the left bronchus (23.5\%). Only one patient had a foreign body at the carina. A total of $58.8 \%$ of the patients had a delayed presentation with a history of $>1$ week, and $44.4 \%$ of the patients after 1 month. History of choking was present in $76.4 \%$ of the cases, which was extracted after the diagnosis. The majority of the foreign bodies was a vegetative foreign body (41\%, supari). One-fourth of the patients had presented with respiratory distress.

A total of $95 \%$ of the patients required a flexible bronchoscopy assessment for diagnosis, since their history was inadequate. All patients underwent high resolution computed tomography (HRCT) of the thorax before the procedure to confirm the position of the foreign body. High resolution computed tomography of the thorax with the reconstruction of the airway is very helpful in identifying the location and to see associated lung changes, for example, Lobar collapse, empyema, consolidation, hyperinflation. We can point out the foreign body in HRCT of the thorax, which will help us to plan intraoperatively. (-Fig. 1) One patient presented with lobar collapse and bronchial stenosis too. - Table 1 highlights the epidemiological and clinical features of the patients included in the present study.

All patients underwent rigid bronchoscopy and foreign body removal under general anesthesia. The patients were oxygenated before the procedure and put in intermittent apnea. Foreign bodies were visualized and removed using the optical grasping forceps by an experienced Otorhinolaryngologist. (-Fig. 2) We noted granulations around the foreign body in $58.8 \%$ of the patients. - Table 2 emphasizes the intraoperative findings.

None of the patients required mechanical ventilation postoperatively. The average hospital stay was noted to be 3.52 days.

\section{Discussion}

Tracheobronchial foreign body aspiration in the pediatric population can present with varying symptoms, ranging
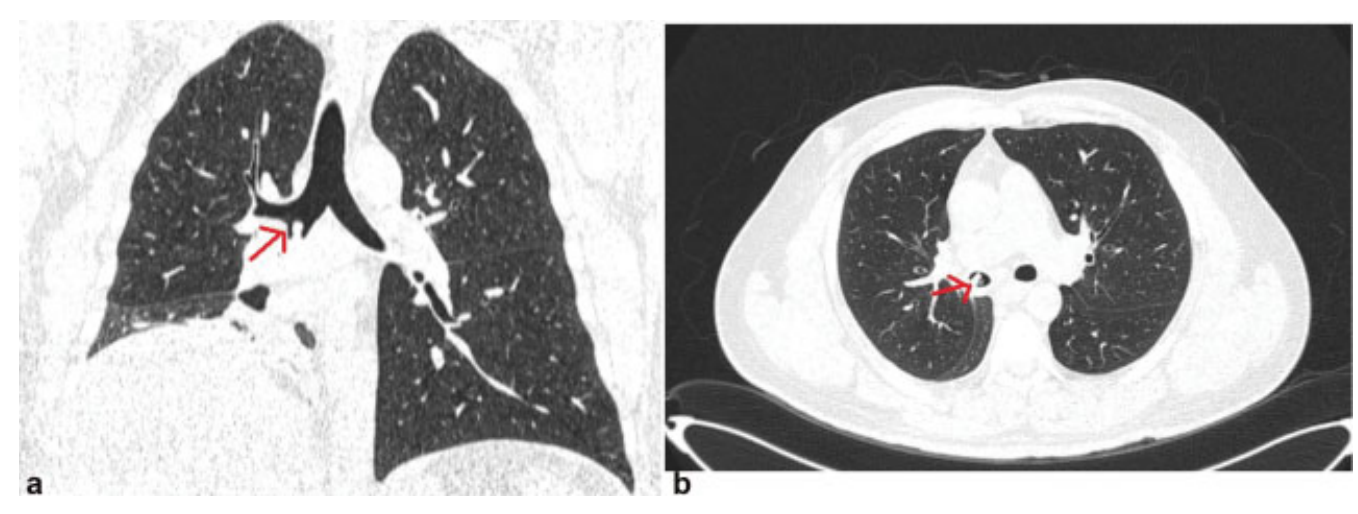

Fig. 1 Showing high resolution computed tomography of the thorax in coronal and axial cuts (Lung window) with probable site of foreign body (marked with red arrow). 
Table 1 Epidemiological and clinical features of patients with tracheobronchial foreign bodies presented to us

\begin{tabular}{|c|c|}
\hline \multicolumn{2}{|l|}{ Age (years old) } \\
\hline$<1$ & $1(5.8 \%)$ \\
\hline $1-5$ & $11(64.7 \%)$ \\
\hline$>5$ & $5(29.4 \%)$ \\
\hline Total & 17 \\
\hline \multicolumn{2}{|l|}{ Gender } \\
\hline Male & $9(52.9 \%)$ \\
\hline Female & $8(47.1 \%)$ \\
\hline \multicolumn{2}{|l|}{ Symptoms } \\
\hline Dry cough & $11 / 17(64.7 \%)$ \\
\hline Respiratory Distress & $9 / 17$ (52.9\%) \\
\hline Fever & $7 / 17(41.17 \%)$ \\
\hline Noisy Breathing & $5 / 17$ (29.4\%) \\
\hline Witnessed choking & $3 / 17(17.6 \%)$ \\
\hline Lethargy & $1 / 17(5.88 \%)$ \\
\hline \multicolumn{2}{|l|}{ Retention Time* } \\
\hline$<24$ hours & $1(5.9 \%)$ \\
\hline 1 day to 7 days & $5(29.4 \%)$ \\
\hline 7 days to 1 month & $3(17.6 \%)$ \\
\hline$>1$ month & $8(47 \%)$ \\
\hline \multicolumn{2}{|c|}{ Associated Chest Finding } \\
\hline $\begin{array}{l}\text { Differential breath } \\
\text { sounds }\end{array}$ & $17 / 17(100 \%)$ \\
\hline $\begin{array}{l}\text { Differential chest } \\
\text { movements }\end{array}$ & $15 / 17(88.2 \%)$ \\
\hline \multicolumn{2}{|l|}{ Radiology Findings } \\
\hline Lobar Collapse & $9 / 17(52.9 \%)$ \\
\hline Hyper inflation & $10 / 17(58.8 \%)$ \\
\hline Consolidation & $12 / 17(70.5 \%)$ \\
\hline
\end{tabular}

*Retention time is calculated as the time of suspected foreign body aspiration until the presentation to us.
Table 2 Intraoperative findings in patients with tracheobronchial foreign body

\begin{tabular}{|c|c|c|}
\hline Serial No. & $\begin{array}{l}\text { Intra operative } \\
\text { findings }\end{array}$ & $\begin{array}{l}\text { Number } \\
\text { (percentage) }\end{array}$ \\
\hline \multirow[t]{3}{*}{1} & \multicolumn{2}{|c|}{ Foreign body found in } \\
\hline & Right Bronchus & 12 \\
\hline & Left Bronchus & 5 \\
\hline \multirow[t]{7}{*}{2} & \multicolumn{2}{|l|}{ Foreign body } \\
\hline & Supari/betel nut & $7(41.1 \%)$ \\
\hline & Peanut & $4(23.5)$ \\
\hline & Ground nut & $3(17.6 \%)$ \\
\hline & Plumseed & $1(5.9 \%)$ \\
\hline & Coconut & $1(5.9 \%)$ \\
\hline & Non-Organic & $1(5.9 \%)$ \\
\hline \multirow[t]{3}{*}{3} & \multicolumn{2}{|c|}{ Intra operative granulations } \\
\hline & Present & $10(58.8 \%)$ \\
\hline & Absent & $7(41.2 \%)$ \\
\hline
\end{tabular}

from a mild cough to severe respiratory distress and even death. Due to delay in the diagnosis, there is significant morbidity in this population. In our study, we noted that $>70 \%$ of patients were $<5$ years old, which was in agreement with other series reported. ${ }^{5,6}$ Extracting the history from parents plays a crucial role in the diagnosis. Atypical history from the parents often misleads the doctors.

The most common foreign body encountered in our series is organic. Betel nut was the most frequent one among our set of cases. Being organic and due to delayed presentation, it was always a challenge to remove these foreign bodies. The most common foreign body seen is peanut among the vegetative, but may differ from region to region. ${ }^{7}$ These differences are mainly due to cultural and social habits in different places.

Diagnostic delays and misdiagnosis are not uncommon. Atypical history from patients often mislead the doctors in making a diagnosis. Foreign body aspiration may mimic other respiratory conditions like asthma, recurrent
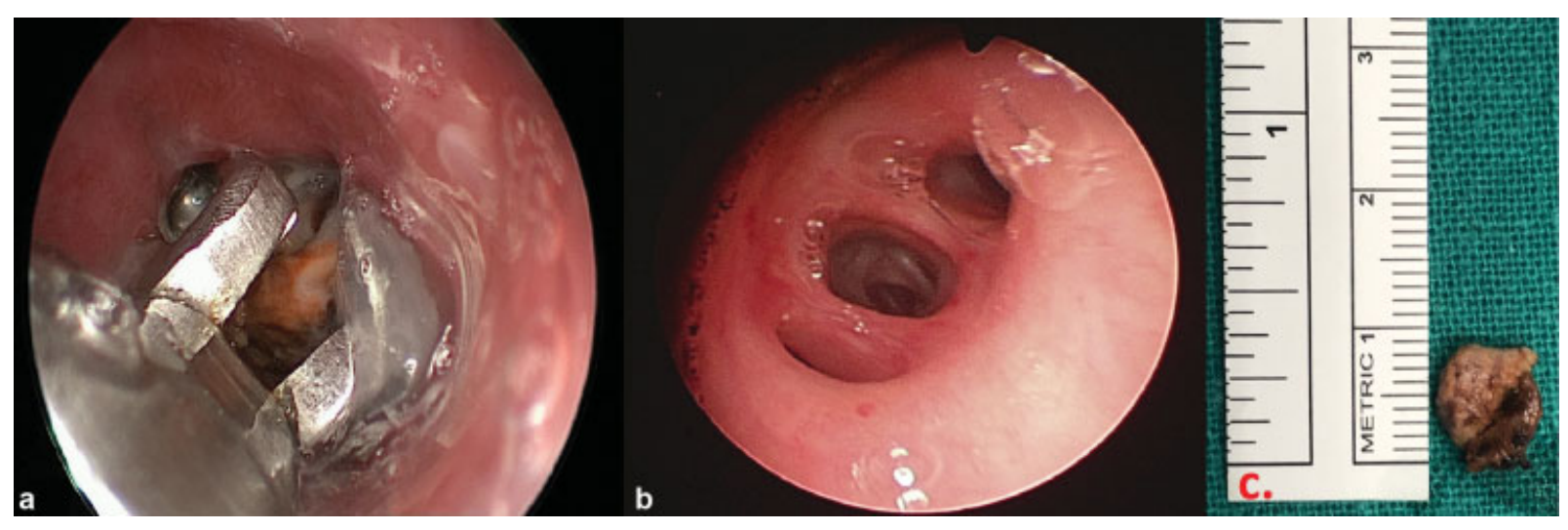

Fig. 2 Intraoperative images showing the removal of the foreign body using optical forceps and postclearance images. We can also see the foreign body $\left(1^{*} 1 \mathrm{~cm}\right)$ 
pneumonia and bronchiolitis. Other common symptoms are fever, chronic cough, wheeze and respiratory distress. The clinician should keep suspicion of foreign body aspiration, especially when a child presents with unilateral lung pathology. The doctor's ability to elicit the history of choking is essential, as it may predict the possibility of foreign body aspiration. Barrios et al. suggested to do bronchoscopy in all children with acute onset respiratory distress, who present with a history of choking. ${ }^{8}$ The most common symptom in our series was cough, which was in agreement with the literature. $^{9}$

A total of $58.8 \%$ of the patients presented after 7 days of the suspected day of aspiration. On reviewing the literature, between 2 and $23 \%$ of the patients present after 1 month. 8,10 In our series, $44.44 \%$ of the patients presented after 1 month.

The retained bronchial foreign body can lead to complications like pneumonia, bronchiectasis, lung abscess and consolidation. ${ }^{8}$ All patients with delayed presentation had a history of multiple admission at different hospitals, and the majority of the time were treated as a case of bronchopneumonia. One patient who presented to us after 1 year had pleural effusion for which intercoastal drainage was performed.

A total of $95 \%$ of the patients underwent flexible bronchoscopy, which helped the diagnosis. Flexible bronchoscopy helped not only to identify the level of the foreign body, but also in assessing the tracheobronchial mucosa.

The role of imaging is also critical in tracheobronchial foreign body diagnosis. ${ }^{11}$ High resolution computed tomography of the thorax was performed in all cases to ascertain the location of the foreign body. In the majority of the times, HRCT had led to the suspicion of tracheobronchial foreign body, which also aided us to confirm the position of the foreign body. We noted that consolidation and hyperinflation were the most common findings. In the case of chronic foreign body aspiration, which is seen in delayed presentation, severe airway inflammation and granulation formation lead to complications.

It is important to note that the management of tracheobronchial foreign bodies requires multiple specialties, including Otorhinolaryngologists, anesthesiologist and pediatric physician. Planning of the definitive management involves the teamwork of these specialties.

The definitive management strategy for tracheobronchial foreign body is rigid bronchoscopy under general anesthesia. In cases where there is a dilemma in diagnosis due to the atypical and long-standing history, there are chances of getting a negative bronchoscopy. In our study, we were able to identify, locate and remove the foreign bodies in all 17 cases. Bronchoscopy findings varied among patients. In most of our delayed presentations, there were more granulation formation and pus discharge at the site of foreign body impaction. Removal of granulation tissue leads to bleeding, which obscures the field. One of our patients had bronchial stenosis due to long term retention of the foreign body. The foreign body was visualized below the stenotic segment. (as seen in - Fig. 3 ).

The technique of foreign body removal also played a key role. All foreign bodies were removed with the aid of optical

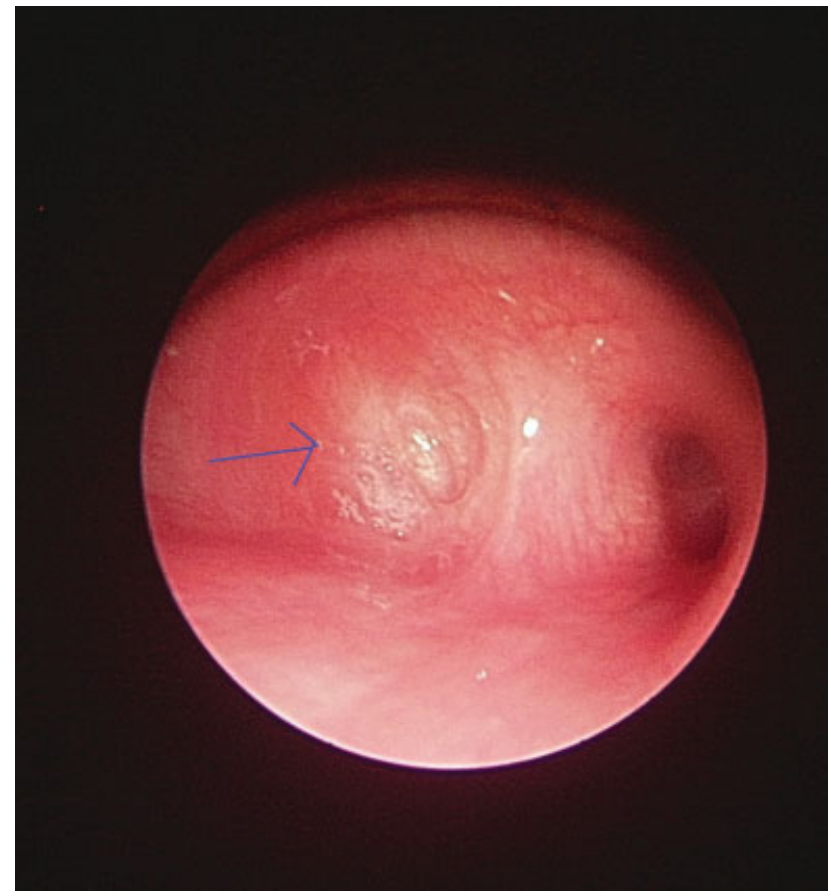

Fig. 3 Showing the stenotic segment (Blue arrow) in the intermediate bronchus in a patient with delayed presentation.

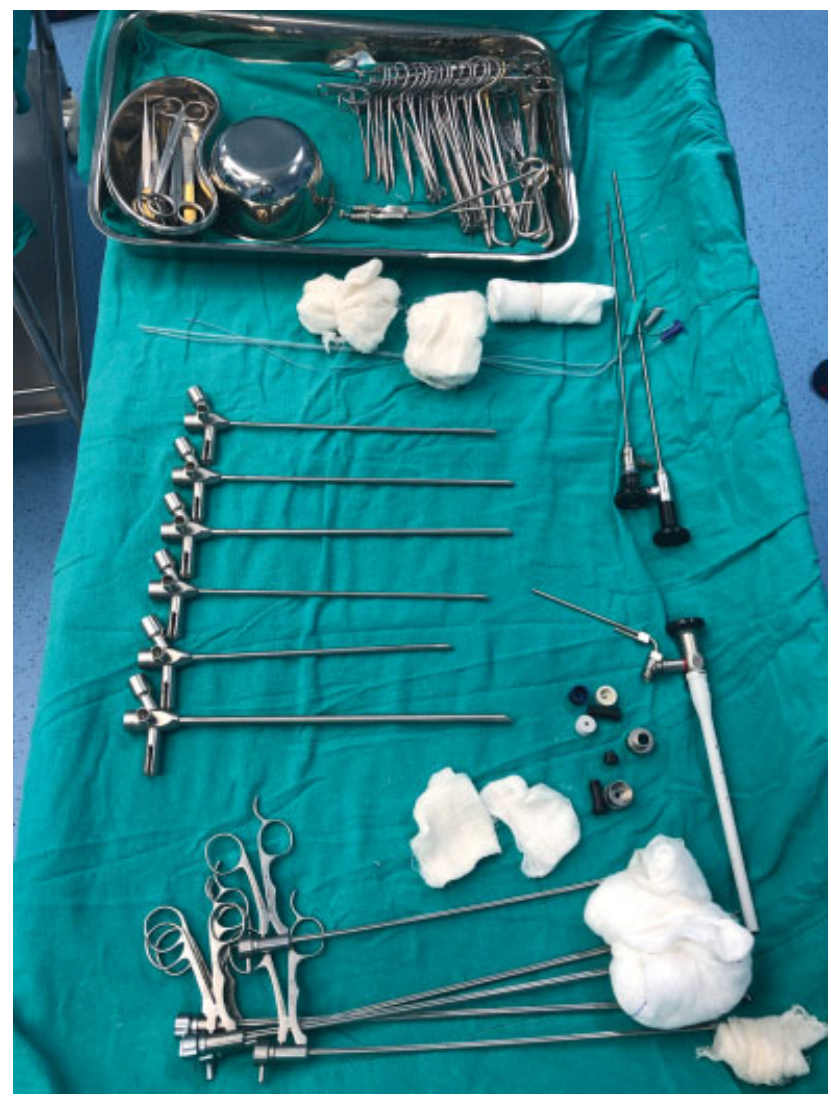

Fig. 4 Showing the instruments including bronchoscope and optical forceps system used during the procedure.

grasping forceps. All the instruments and endoscope have to be checked and arranged on a tray. (-Fig. 4) We used to practice with instruments prior to the procedure with gauze piece or syringe caps, to ensure the grasp of instruments. 
With the help of optical forceps, foreign bodies were better visualized and hence aided the management without any complications. While removing the foreign body, the rigid bronchoscope was held much more proximal, preferably at the level of the carina, to avoid injury to the bronchus.

In all 17 cases, bronchoscopy and foreign body removal were successful without any complications. All patients were managed postoperatively with I/V antibiotics, nebulization and other supportive treatment.

\section{Conclusion}

In our experience, delayed presentations of lower airway foreign body aspiration were always associated with mild to severe form of complications. Whenever a child presents with respiratory symptoms that do not improve with usual medications, the clinician should have a high index of suspicion. We should be more vigilant in history taking and clinical examination. Preoperative planning, multidisciplinary teamwork, surgeon expertise and technique are the key factors in avoiding complications in the definitive management. A high index of suspicion and early intervention is needed to prevent complications.

Conflict of Interests

The authors have no conflict of interests to declare.

\section{References}

1 Altuntas B, Aydın Y, Eroglu A. Foreign Bodies in Trachea: A 25years of Experience. Eurasian J Med 2016;48(02):119-123

2 Narasimhan KL, Chowdhary SK, Suri S, Mahajan JK, Samujh R, Rao KLN. Foreign body airway obstructions in children- lessons learnt from a prospective audit. J Indian Assoc Pediatr Surg 2002; 7:184-189

3 Eroğlu A, Kürkçüoğlu IC, Karaoğlanoğlu N, Yekeler E, Aslan S, Başoğlu A. Tracheobronchial foreign bodies: a 10 year experience. Ulus Travma Acil Cerrahi Derg 2003;9(04):262-266

4 Svedström E, Puhakka H, Kero P. How accurate is chest radiography in the diagnosis of tracheobronchial foreign bodies in children? Pediatr Radiol 1989;19(08):520-522

5 Banerjee A, Rao KS, Khanna SK, et al. Laryngo-tracheo-bronchial foreign bodies in children. J Laryngol Otol 1988;102(11):1029-1032

6 Kim IG, Brummitt WM, Humphry A, Siomra SW, Wallace WB. Foreign body in the airway: a review of 202 cases. Laryngoscope 1973;83(03):347-354

7 Burton EM, Brick WG, Hall JD, Riggs W Jr, Houston CS. Tracheobronchial foreign body aspiration in children. South Med J 1996; 89(02):195-198

8 Barrios JE, Gutierrez C, Llana J, et al. Bronchial foreign body: Should bronchoscopy be performed in all patents with a choking crisis. Pediatr Surg Int 1997;12:118-120

9 Saquib Mallick M, Rauf Khan A, Al-Bassam A. Late presentation of tracheobronchial foreign body aspiration in children. J Trop Pediatr 2005;51(03):145-148

10 Wiseman NE, Schwartz I. The diagnosis of foreign body aspiration in childhood. J Pediatr Surg 1984;19(05):531-535

11 Tokar B, Ozkan R, Ilhan H. Tracheobronchial foreign bodies in children: importance of accurate history and plain chest radiography in delayed presentation. Clin Radiol 2004;59(07):609-615 